Published in final edited form as:

J Dev Orig Health Dis. 2016 December ; 7(6): 602-615. doi:10.1017/S204017441600043X.

\title{
Early Inherited Risk for Anxiety Moderates the Association between Fathers' Child-Centered Parenting and Early Social Inhibition
}

\author{
Rebecca J. Brooker, \\ Montana State University \\ Kathleen M. Alto, \\ University of Akron \\ Kristine Marceau, \\ Brown University \\ Reema Najjar, \\ Montana State University \\ Leslie D. Leve, \\ University of Oregon \\ Jody M. Ganiban, \\ George Washington University \\ Daniel S. Shaw, \\ University of Pittsburgh \\ David Reiss, and \\ Yale Child Study Center \\ Jenae M. Neiderhiser \\ The Pennsylvania State University
}

\begin{abstract}
Studies of the role of the early environment in shaping children's risk for anxiety problems have produced mixed results. It is possible that inconsistencies in previous findings result from a lack of consideration of a putative role for inherited influences moderators on the impact of early experiences. Early inherited influences not only contribute to vulnerabilities for anxiety problems throughout the lifespan, but can also modulate the ways that the early environment impacts child outcomes. In the current study, we tested the effects of child-centered parenting behaviors on putative anxiety risk in young children who differed in levels of inherited vulnerability. We tested this using a parent-offspring adoption design and a sample in which risk for anxiety problems and parenting behaviors were assessed in both mothers and fathers. Inherited influences on anxiety problems were assessed as anxiety symptoms in biological parents. Child-centered parenting was
\end{abstract}

Correspondence concerning this article should be addressed to Jenae Neiderhiser, 222 Moore Building, The Pennsylvania State University, University Park, PA 16802; jenaemn@ psu.edu or to Rebecca Brooker, Montana State University Department of Psychology; PO Box 173440, Bozeman, MT 59718; rebecca.brooker@montana.edu. 
observed in adoptive mothers and fathers when children were 9 months old. Social inhibition, an early temperament marker of anxiety risk, was observed at child ages 9 and 18 months. Inherited influences on anxiety problems moderated the link between paternal child-centered parenting during infancy and social inhibition in toddlerhood. For children whose birth parents reported high levels of anxiety symptoms, greater child-centered parenting in adoptive fathers was related to greater social inhibition 9 months later. For children whose birth parents reported low levels of anxiety symptoms, greater child-centered parenting in adoptive fathers was related to less social inhibition across the same period.

Social inhibition, defined as withdrawal and reduced activity in novel social contexts, is an early marker of risk for the development of anxiety problems (Biederman et al., 2001; Chronis-Tuscano et al., 2009; Clauss \& Blackford, 2012). Social inhibition is typically negatively linked to child-centered parenting behaviors, which emphasize parental responsiveness, engagement, and the anticipation of children's needs, moods, and desires; however, the direction of this association is inconsistent (Crockenberg \& Leerkes, 2004; Degnan, Henderson, Fox, \& Rubin, 2008; Natsuaki et al., 2013; Park, Belsky, Putnam, \& Crnic, 1997). Developmental theory depicts parents as early scaffolds that shape children's outcomes (Kopp, 1982). Such postulates largely ignore the reciprocal influence of childbased characteristics on behaviors in parents (Bell, 1968; Cicchetti \& Cohen, 2006; Davidov, Knafo-Noam, Serbin, \& Moss, 2015). The absence of child-based effects may help to explain discrepancies in the direction of association between child-centered parenting, which combines traditional definitions of parental sensitivity, responsivity, and involvement, with child outcomes. For example, levels of inherited vulnerability in children (e.g., the propensity to be socially inhibited) may modulate effects of the early environment to predict outcomes such as social inhibition (Belsky \& Pluess, 2009; Boyce \& Ellis, 2005; Reiss, Leve, \& Neiderhiser, 2013). Consistent with this notion, highly child-centered behaviors may be detrimental for more vulnerable children to the degree that they preclude the development of independent self-regulation. In the current study, we used a parent-offspring adoption design to test whether early inherited influences on anxiety problems moderated associations between child-centered parenting and social inhibition during infancy.

\section{Social Inhibition and Risk for Anxiety Problems}

Temperament describes a rubric of constitutionally-based behavioral phenomena from which predictions about links between early individual differences and developmental outcomes can be cast (Goldsmith et al., 1987). Inhibited temperament, manifest as high levels of reactivity and avoidance of novelty (Kagan, 1984; 1994), is a risk factor for the development of anxiety problems, with higher levels of inhibition in infancy associated with more symptoms of social anxiety (Biederman et al., 2001; Chronis-Tuscano et al., 2009; Hirshfeld-Becker et al., 2007; Natsuaki et al., 2013). Because early inhibition is most robustly associated with risk for social anxiety problems, (Hirshfeld-Becker et al., 2007), we and others have focused on social inhibition, or inhibited behaviors in contexts of social novelty (Brooker et al., 2011; Brooker, Kiel, \& Buss, in press; Volbrecht \& Goldsmith, 2010), as a marker of early risk. As expected, social inhibition during infancy shows positive associations with risk for the development of social anxiety symptoms (Brooker et al., 2011; 
Prior, Smart, Sanson, \& Oberklaid, 2000; Stemberger, Turner, Beidel, \& Calhoun, 1995). This definition of social inhibition overlaps, both in characterization and in predicted outcomes, with additional markers of risk for anxiety problems in young children (Buss \& McDoniel, 2016; Degnan et al., 2014).

\section{Child-Centered Parenting, Inhibition, and Anxiety Risk}

Despite demonstrated prediction, the correspondence between early inhibition and high levels of anxiety symptoms is low to moderate from infancy through middle childhood (Hirshfeld et al., 1992). This lower-than-expected stability has resulted in efforts to identify potential moderators of the association between early inhibition and later anxiety problems. A small subset of research has examined associations between parenting behaviors and emerging inhibition (Degnan et al., 2008). Findings suggest that child-centered parenting, which we view as a broad construct comprising traditional definitions of involved, responsive and supportive behaviors, tends to be negatively associated with inhibition during infancy (Crockenberg \& Leerkes, 2004; Natsuaki et al., 2013) and anxiety symptoms in inhibited toddlers (Crockenberg \& Leerkes, 2006; Warren \& Simmens, 2005). Although these associations may, too, be reciprocal, the primary theoretical framework for their interpretation characterizes caregivers as scaffolds for the development of regulatory behaviors in children (Kopp, 1982). From this perspective, parents recognize and seize opportunities to teach their children how to appropriately regulate inhibition, which diminishes the severity of inhibited behaviors and long-term risk for anxiety problems. Such a pathway to positive outcomes is likely to be most visible when parent behaviors are keenly attuned to the needs of the child (Chess \& Thomas, 1977)

In some instances, child-centered behaviors also appear to exacerbate early inhibition (Degnan et al., 2008; Park et al., 1997). Temperamentally reactive infants who experienced more child-centered parenting behaviors were behaviorally-inhibited as toddlers (Park et al., 1997), an association not observed among less reactive infants. Perhaps most surprisingly, greater sensitivity (attunement of parent behavior to child needs) and positive affect (expressed positive emotion) in fathers was associated with higher levels of inhibition 1 year later. Again, the lens for interpreting this finding focuses on parents as facilitators of developing of regulatory skills in their children. Arcus and colleagues (1992) have suggested that such patterns of effects reflect parents' acceptance of, rather than efforts to change, children's inabilities to cope in negative contexts. That is, for inhibited children in particular, it is possible that parents' attunement to and focus on the child's high levels of fear may interfere with, rather than promote, children's development of independent strategies for regulating fearfulness (Kagan, 1994) and increase long-term risk for internalizing problems (Kiel \& Maack, 2012).

\section{Heritable Child Characteristics Modulate Effects of Parental Behaviors}

Findings such as those described above naturally suggest that children's own characteristics may modulate the effects of parents' child-centered behaviors. For example, sensitive parents are often characterized as attuning their own behaviors to the behavior of their child. However, as described, the degree to which this is beneficial for the child's long-term 
adjustment may depend on the child's own characteristics. Mothers of anxious children show very high levels of child focus on their child when their children experience negative affect (Hudson, Comer, \& Kendall, 2008) and may take on the task of regulating the child's negativity for him/her, understanding that the child cannot do so alone. Although this behavior would be highly responsive to and focused on the child's immediate needs, there is evidence that a more contextually insensitive, less attuned response may be more beneficial for inhibited children over time, forcing practice with the regulation of fear and negativity (Park et al., 1997). In this way, the child's own characteristics play a crucial role in determining whether parent behaviors lead to beneficial or detrimental outcomes over time.

To our knowledge, only one report has shown that low and high levels of child-centered behavior are differentially associated with anxiety symptoms in children based on levels of inhibition. A cross-sectional study by Mount and colleagues (2010) reported that for toddlers low in early inhibition, greater parent sensitivity, a measure including child-centered behaviors, was associated with fewer anxiety symptoms. For toddlers high in early inhibition, greater parent sensitivity predicted more anxiety symptoms. These results support the idea that infant temperament plays an important role in the degree to which childcentered behaviors in parents prove beneficial for children's anxious behaviors.

Surprisingly, the possibility that heritable factors may moderate the degree to which childcentered parenting behaviors are adaptive or maladaptive has not been directly examined. Inherited biological factors appear to contribute to internalizing problems, including social inhibition, from early life. Profiles reflecting developmental pathways of social fear between 6 and 36 months of age are roughly 40\% heritable (Brooker et al., 2013) and covariation among infants' observed and parent-reported inhibition to strangers may be entirely attributable to genetic factors (Goldsmith, Lemery, Buss, \& Campos, 1999). Similar levels of heritability for socially inhibited behaviors have been reported in older children (Matheny, 1989) and adults (Plomin, 1986). Thus, children of anxious birth parents may inherit a propensity to develop anxiety problems, manifest early in life as social inhibition. In the same way, nonanxious birth parents may transmit, through heritable factors, a low risk for the development of anxiety problems in their offspring.

Inherited liabilities for anxiety problems are not only transmitted to offspring, but may also influence maternal and paternal behaviors, typically thought of as "environmental" influences on child outcomes, through evocative effects on parenting. For example, at least one study has shown that mothers displayed less warmth and granted less autonomy to anxious relative to nonanxious children (Moore, Whaley, \& Sigman, 2004). That such effects were observed regardless of mothers' own levels of anxiety suggests that anxious children may elicit more negative parenting behaviors than do nonanxious children. If the same heritable factors influence both parenting behaviors and children's levels of social inhibition, it is not possible to disentangle environmental from inherited effects using traditional research designs. This impossibility arises because children and parents share the same heritable liabilities and early environment. In a parent-offspring adoption design, however, such influences are distinct because adoptive parents raise children to whom they are genetically unrelated and birth parents are not part of the rearing environment. Because only adoptive parents provide the adopted child's rearing environment, associations between 
adoptive parents' characteristics and the child's behavior are best explained as environmental. Similarly, when appropriate prenatal factors are controlled, associations between birth parent characteristics and child behavior are best explained as heritable influences (Leve et al., 2013). The current study used a parent-offspring adoption design to test whether inherited characteristics moderated the association between child-centered parenting and social inhibition across infancy and toddlerhood.

\section{Prenatal Influences on Child Outcomes}

In addition to biological factors, the parent-offspring adoption design enables the examination of a range of prenatal environmental influences on child development that are independent from early parenting. For example, substance use, physical ailments, and toxin exposure in birth mothers during pregnancy have been positively associated with maladjustment in young children (Marceau et al., 2013; Mattson \& Riley, 2000; Mill \& Petronis, 2008). Of particular importance for the current study, these prenatal risk factors showed small but significant positive associations with children's withdrawal and emotional reactivity as early as the toddler years (Marceau et al., 2013). While such factors need to be controlled to appropriately test heritable factors as moderators associations between childcentered parenting and child outcomes, it is also possible that they represent independent influences on the early environment and child outcomes. Yet, few studies have explicitly tested the contributions of prenatal factors to developing social inhibition in children. A parent-offspring adoption design provides an ideal opportunity to test this possibility given that prenatal factors are not confounded with the early environment. Therefore, as an additional test of early influences on child outcomes, prenatal substance use, medical problems, and toxin exposure were included in the current study as both covariates of the proposed moderation and as exploratory predictors of the impact of prenatal factors on the development of social inhibition.

\section{Maternal and Paternal Caregiving}

Finally, it merits consideration that inconsistencies in previous work may result from inadequate assessments of the parenting environment. To date, research has largely excluded fathers from studies of parenting despite the idea that fathers comprise a part of the early parenting environment for a large number of children. A recent meta-analysis of studies of attachment suggested that child-centered behaviors functioned similarly in fathers and mothers (Lucassen et al., 2011). One can, then, imagine instances in which children may experience only limited occasions of warm, sensitive, responsive interactions with one parent, but a large number of these types of interactions with another parent which buffer against negative outcomes. Similarly, given that both maternal and paternal symptoms are associated with risk for the development of anxiety problems (Dierker, Merikangas, \& Szatmari, 1999), it is possible that chronic exposure to two anxious parents enhances risk relative to being reared by only one anxious parent. On the other hand, if the impact of child-centered parenting is not equal across parents, the possibility that modulating effects exist may be ruled out. Based on this possibility, we also examined fathers' parenting in the current work. Given a relative absence of research on fathers in the extant literature, we conducted separate tests for mothers and fathers in the current report to test whether 
parenting behaviors in mothers and fathers impact children in the same ways. Differences in findings for maternal and paternal behaviors were tested using a multi-group comparison.

\section{The Current Study}

We tested whether inherited influences on risk for anxiety problems moderated the association between child-centered parenting behaviors and early social inhibition. Based on the extant literature, we hypothesized that greater child-centered behavior during infancy would be associated with lower levels of social inhibition in toddlers whose birth parents were low in anxiety. We also hypothesized that greater child-centered behavior during infancy would be associated with greater social inhibition in toddlers whose birth parents were high in anxiety. We expected that these associations would not be significantly different in mothers and fathers.

We also conducted exploratory analyses of the impact of a broad range of pregnancy complications on developing social inhibition in young children. Consistent with a small amount of past research, we expected that more pregnancy complications would be associated with greater levels of social inhibition.

\section{Method}

\section{Participants}

Participants were drawn from the Early Growth and Development Study (EGDS; Leve et al., 2013). EGDS is a multisite longitudinal study of 561 physically healthy, domestically adopted children in the United States and their birth and adoptive parents collected in two cohorts. In order to participate, the following criteria had to be met: (1) the adoption placement was domestic, (2) infants were placed in their adoptive homes within 3 months of birth, (3) infants were placed with an unrelated adoptive family, (4) infants had no known major medical conditions such as extreme prematurity or extensive medical surgeries, and (5) the birth and adoptive parents read or understood English at the $8^{\text {th }}$-grade level. Given questions about potential differences between the effects of maternal and paternal parenting, participants were limited to families with two heterosexual parents $(n=503)$. Fathers in families who were included in data analyses showed slightly fewer child-centered behaviors than fathers of families who were not included $(t=2.10, p<0.05, d=0.33)$. Similarly, excluded families were more highly educated than included families (mothers: $t=2.92, p<$ $0.01, d=0.48$; fathers: $t=2.54, p<0.05, d=0.45$ ). Included families did not differ from excluded families on any other study variables.

The majority $(70.1 \%$ ) of birth mothers were Caucasian (African-American $=13.3 \%$, American Indian or Alaska Native $=2.5 \%$, Asian $=1.8 \%$, Native Hawaiian or Pacific Islander $=0.2 \%$, Hispanic or Latina $=6.7 \%$, more than 1 race $=4.9 \%$, Unknown $/$ did not report $=0.5 \%)$, as were birth fathers $($ Caucasian $=69.9 \%$, African-American $=11.5 \%$, American Indian or Alaska Native $=0.5 \%$, Native Hawaiian or Pacific Islander $=0.5 \%$, Hispanic or Latino $=9.6 \%$, more than 1 race $=4.8 \%$, Unknown $/$ did not report $=3.3 \%$ ). Most birth parents had completed at least a high school degree and earned between $\$ 15,001$ and $\$ 25,000$ (birth mothers) or $\$ 25,001$ and $\$ 40,000$ (birth fathers) annually. 
The majority (91.8\%) of adoptive mothers were Caucasian (African-American $=3.9 \%$, American Indian or Alaska Native $=0.2 \%$, Asian $=0.9 \%$, Hispanic or Latina $=2 \%$, more than 1 race $=0.9 \%$, Unknown $/$ did not report $=0.4 \%$ ), as were adoptive fathers (Caucasian $=$ $90.4 \%$, African-American $=4.9 \%$, Asian $=0.5 \%$, Native Hawaiian or Pacific Islander $=$ $0.5 \%$, Hispanic or Latino $=1.6 \%$, more than 1 race $=1.1 \%$, Unknown $/$ did not report $=$ $1.6 \%)$. Median values suggested that most adoptive parents had completed at least a 4-year college degree and earned between $\$ 25,001$ and $\$ 40,000$ (adoptive mothers) or $\$ 70,001$ and $\$ 100,000$ (adoptive fathers) annually. Eligible families who enrolled in the study did not differ from those who declined on education level, income, or age. Infants were placed in adoptive homes a mean of 6.19 days after birth $(S D=12.45)$. Full details of the EGDS design, recruitment procedures, and sample can be found elsewhere (Leve et al., 2013).

\section{Procedure and Measures}

As a part of the EGDS design, children, their birth parents, and their adoptive parents participated in multiple assessments across the infant and toddler period. Trained research assistants visited the homes of children and their adoptive parents when children were 9 and 18 months of age. Adoptive parents also completed questionnaires at the time of the home visits. Birth parents were contacted by phone to complete a number of screenings and questionnaires when adopted children were between roughly 5 and 18 months of age (Birth mothers: $M=5.96, S D=2.60$; Birth fathers: $M=18.66, S D=4.75$ ).

Heritable Influences: Birth parent anxiety symptoms-Anxiety symptoms in birth mothers $(n=497)$ and birth fathers $(n=170)$ were assessed via self-report using the total number of symptoms reported on the Beck Anxiety Inventory (BAI; Beck \& Steer, 1993) when children were 3-6 months of age. Birth parents were asked to indicate the degree to which they experienced symptoms of anxiety on a 4-point scale $(1=$ not at all, $4=$ severely $)$. Individual items were summed to create an overall score of anxiety symptoms for each participant. Reliability of the BAI total problems scale was for high for both birth mothers $(a=.91)$ and birth fathers $(a=.88)$. BAI scores from $0-7$ are interpreted as minimal anxiety, 8-15 as mild anxiety, 16-25 as moderate anxiety, and 26-63 as severe anxiety. For birth mothers, scores of overall anxiety ranged from $0-52(n=497, M=9.92, S D=9.10)$. For birth fathers, scores of overall anxiety ranged from 0-38 $(n=170, M=8.20, S D=8.23)$. Scores of overall anxiety for birth mothers and birth fathers were not significantly correlated $(r=.10, p>.10)$. However, because parents contribute equally to the genetic makeup of their biological children, we chose to conceptualize inherited risk for anxiety symptoms in adoptive children as the maximum number of anxiety symptoms in birth mothers and birth fathers. For cases for which no birth father data were available, heritable influences reflect birth mother influences only.

Early environment: Observed child-centered behaviors-As previously stated, we view child-centered parenting as a broad construct that encompasses traditional definitions of involved, responsive, and sensitive parenting - each of which has been associated with childhood fear and inhibition in past research. During the home visit when children were 9 months of age, adoptive parents each participated in a 3-minute teaching activity with their infant. For this, each parent was given a puzzle (moms: stacking blocks and rings; dads: 
shape sorter) and told that the task was for the child to solve the puzzles. Parents were told that the child should complete the task on his/her own, but that parents could offer help if it became necessary.

Videotapes of the teaching tasks were scored for child-centered behaviors according to a previously-established coding scheme (Dogan et al., 2005). Child-centered behavior was coded when the parent's verbal and nonverbal behaviors toward the child met the following characteristics: (1) displayed an awareness of the child's needs, moods, interests, and capabilities, (2) anticipated the child's needs, (3) were well-timed and appropriate with the child's behavior and mood, and (4) were responsive to the child's behavior and vocalizations. Ratings were made on a 9-point scale ranging from not at all characteristic (1) to mainly characteristic (9) of parents' behaviors. Roughly $20 \%$ of cases were double coded to establish reliability. Coding reliabilities were high for both adoptive mothers $(r=0.90)$ and adoptive fathers $(r=0.89)$. Scores of child-centered behaviors for mothers $(n=436, M=$ $5.91, S D=1.66)$ were greater than scores for fathers $(n=436, M=5.52, S D=1.75 ; t(435)$ $=3.72, p<.01, d=0.23)$. Therefore, although scores of child-centered behaviors for mothers and fathers were significantly correlated $(r=0.21, p<.01)$, we examined childcentered parenting separately for adoptive mothers and adoptive fathers.

Adoptive parent anxiety symptoms-Levels of adoptive parent anxiety symptoms were assessed via self-report using the Beck Anxiety Inventory (BAI; Beck \& Steer, 1993) when children were 9 months of age. Adoptive mothers and adoptive fathers were asked to indicate the degree to which they experienced different symptoms of anxiety on a 4-point scale $(1=$ not at all, $4=$ severely $)$. Individual items were summed to create an overall score of anxiety symptoms. Reliability of the BAI total problems scale was for high for adoptive mothers $(a=.75)$ and adoptive fathers $(a=.73)$. For adoptive mothers, scores of overall anxiety ranged from $0-21(n=496, M=3.82, S D=3.60)$. For adoptive fathers, scores of overall anxiety ranged from $0-19(n=478, M=3.03, S D=3.16)$. Scores of overall anxiety for adoptive mothers and fathers were modestly correlated $(r=.13, p<.01)$.

Although adoptive parent anxiety symptoms were not central to the aims of this study, including this measure in analyses allowed for three areas of investigation. First, because it is present in the analysis model, adoptive parent anxiety is partialed out of other variables, allowing us to be confident that associations between other factors are not the result of a common link to adoptive parent anxiety. Second, including adoptive parent anxiety symptoms allowed for a test of a second, more distal set of environmental effects. That is, we were able to examine the association between adoptive parent anxiety symptoms and child social inhibition separately from the association between adoptive parents' childcentered behaviors and child social inhibition. Finally, because birth and adoptive parents were not typically in direct contact, predicting adoptive parent anxiety symptoms from our proxy of children's heritable risk (i.e., birth parent anxiety symptoms) allowed for a test of evocative effects on adoptive parent anxiety. That is, we examined whether early inherited characteristics of the child other than social inhibition might evoke anxiety symptoms in adoptive parents. 
Observed social inhibition-During home visits when children were 9 and 18 months of age, children participated in multiple episodes designed to measure a range of behaviors associated with child functioning. At both 9 and 18 months, the current study used an interaction with a stranger that was designed to assess social inhibition in infants. The interaction was comprised of four 30 -sec intervals. For the first $30 \mathrm{sec}$ of the interaction, a stranger sat quietly and neutrally on the floor near the child. Parents were present and nearby, but remained uninvolved throughout the episode. For the following $30 \mathrm{sec}$, the stranger remained neutral while building a tower of stacked cups. In the third interval, the stranger invited the child to play. Children were given $5 \mathrm{sec}$ to engage in play. If they did not, the stranger unstacked the cups. For the final $30 \mathrm{sec}$, the stranger fully interacted with the child by smiling and encouraging him/her to participate in building and knocking down the tower. At the end of four minutes, the stranger thanked the child and moved on to the next activity.

Videotapes of the stranger interaction were scored for behaviors based on a previously established coding scheme (Kochanska, 1991). Infants were rated on 4-point scales for their inhibition to the stranger, inhibition of exploration, activity level, and proximity to caregiver during the episode. Scale anchors were assigned such that higher scores indicated greater social inhibition. Ratings were assigned by 4 independent coders. Scores were assigned in 30 -sec intervals and then collapsed by averaging scores across the interaction. Each coder was required to achieve a minimum reliability of Pearson's $r=.85$ with a master coder before coding cases independently. Fifteen percent of videos were double coded to calculate inter-rater reliabilities and prevent coding drift. The mean reliability across behaviors was $r$ $=.90$ (9 months) and $r=.92$ (18 months). All coded behaviors were significantly correlated. Infant social inhibition was therefore quantified as the mean of ratings across scales.

\section{Covariates}

Pregnancy complications-Multiple self-report measures collected 5 months postpartum were used to score pregnancy and delivery complications. Birth mothers used a pregnancy screener and pregnancy history calendar to report on medical aspects of pregnancy as well as instances of substance use, toxin exposure, and health complications during pregnancy. Overall risk status for the fetus was calculated as a weighted sum of totals from individual measures (Marceau et al., 2013).

Openness of adoption-Birth and adoptive parents were asked to self-report, on a 7point scale, the extent to which they perceived that their adoption to be open, where openness is characterized by contact, disclosure, and and communication between birth and adoptive parents (Grotevant, McRoy, Elde, \& Fravel, 1994). Parent reports were obtained when children were 5 (birth parents) and 9 (adoptive parents) months old. Scores ranged from very closed (1) to very open (7). The standardized mean of ratings from birth mothers, adoptive mothers, and adoptive fathers was used to statistically control for effects that might otherwise arise as a result of contact between birth and adoptive parents $(M=0.03, S D=$ 0.91 ). 
Sex of infant-Sex of infant was scored based on a dummy code system $(1=$ male, $2=$ female). The current sample was comprised of $57.3 \%$ males. Given some evidence that sex of child is associated with social inhibition (Kagan, 1984) and with parenting behaviors (Lytton \& Romney, 1991), sex of child was used as a control variable for all analyses.

Adoptive parent education-Levels of parent education have previously been associated with parenting behaviors (Hoff, Laursen, \& Tardif, 2002); for example, more educated parents are more child-centered than less educated parents (Bluestone \& TamisLeMonda, 1999). Therefore, parent education in the adoptive home was accounted for in the current analyses. Adoptive parents self-reported their maximum level of education on a 7point scale ranging from less than a high school degree (1) to graduate degree (7).

Missing Data-All primary variables met the criteria of minimum covariance coverage $=$ 0.10 (range: $0.55-1.00$ ). Ratings of maternal and paternal parenting behavior were missing for 44 and 65 children, respectively. Levels of social inhibition at the 18-month assessment were missing for 194 children. Missing data were the result of nonparticipation at a particular assessment, technical difficulties, and/or uncodable video.

A test of patterns of missing data suggested that data were missing at random (MAR; Little's $\left.\operatorname{MCAR} \chi^{2}(165)=165, p<.01\right)$. Children with 18-month assessment data were placed into their adoptive homes earlier $(t=2.03, p<0.05, d=0.20)$, were less inhibited at 9 months of age $(t=2.06, p<0.05, d=0.68)$, and had adoptive mothers $(t=-3.42, p<0.01, d=-0.32)$ and fathers $(t=-2.53, p<0.05, d=-0.25)$ who showed more child-centered behaviors at age 9 months than children without 18-month data. Families with and without data on primary variables did not differ on any other metrics. Statistical analyses were conducted in Mplus, which uses a Full Information Maximum Likelihood procedure to account for missing data in dependent variables. This procedure is known to produce less biased parameter estimates than a complete-cases-only analyses and has been shown to appropriate for use with MAR data, particularly when variables that are associated with missingness are included in the statistical model (Enders, 2010).

\section{Results}

\section{Descriptive Statistics and Bivariate Associations}

Means and standard deviations for study variables are shown in Table 1. All variables were normally distributed. On average, birth parents reported experiencing mild anxiety, though the full range of anxiety symptoms was present. Correlations among study variables are presented in Table 2. Greater maternal child-centered parenting was also associated with greater 9-month inhibition.

\section{Heritable Factors as Moderators of Risk for Social Inhibition}

We tested whether inherited influences moderated the association between child-centered parenting behaviors and social inhibition using a multivariate regression model in Mplus. Maternal child-centered parenting and paternal child-centered parenting were tested separately, however maternal and paternal models were structured in the same way. In the 
first analysis, openness of adoption, placement age, adoptive parent education, and pregnancy complications served as covariates for all other variables. Placement age and openness of adoption were allowed to correlate, as was recommended by model modification indices ( $\mathrm{MI}>10$ ). Birth parent anxiety symptoms, adoptive parent anxiety, child-centered parenting, and previous levels of social inhibition served as primary predictors. The interaction between child-centered parenting and birth parent anxiety symptoms provided a test of the moderation of effects of child-centered parenting by early inherited influences. The full model (excluding covariates) is shown in Figure 1. Variables were centered prior to the creation of interaction terms. The interaction between levels of birth parent anxiety and child-centered parenting was not partialled out of other variables so that results could be interpreted as main, rather than simple, effects (Aiken \& West, 1991).

\section{Maternal child-centered parenting}

In the model for adoptive mothers, several associations emerged between control and primary study variables (Table 3). Only openness of adoption predicted social inhibition in children at age 18 months such that greater openness predicted less inhibition over time (Figure 2; $B=-0.13, S E(B)=0.06, p=0.02$ ). However, greater openness also predicted greater anxiety in adoptive mothers $(B=0.59, S E(B)=0.18, p<0.01)$. Higher levels of education in adoptive mothers predicted more child-centered behaviors $(B=0.25, \operatorname{SE}(B)=$ $0.06, p<0.01)$. More pregnancy complications were associated with greater social inhibition at 9 months of age $(B=0.06, \operatorname{SE}(B)=0.02, p=0.02)$. Children's social inhibition showed low levels of stability between the two assessments $(B=0.05, \operatorname{SE}(B)=0.04, p=0.16)$.

Analyses including primary study variables suggested an absence of direct heritable effects on children's social inhibition. That is, birth parent anxiety symptoms were not associated with children's social inhibition at 9 months of age $(B=-0.01, \operatorname{SE}(B)=0.01, p=0.49)$ or $18(B=0.00, \operatorname{SE}(B)=0.01, p=0.53)$. We did, however, see evidence for evocative effects of heritable influences on maternal child-centered parenting behaviors. Specifically, greater birth parent anxiety was positively associated with adoptive mothers' child-centered behaviors $(B=0.02, \operatorname{SE}(B)=0.01, p=0.02)$, suggesting that greater propensities for anxiety symptoms may evoke greater child-centered behaviors in adoptive mothers. Similarly, greater social inhibition in children at 9 months of age was associated with greater child centered behaviors in adoptive mothers at the same assessment $(B=0.20 \mathrm{SE}(B)=0.08, p=$ $0.01)$.

Adoptive mother anxiety was not associated with maternal child-centered parenting ( $B=$ $0.01, \operatorname{SE}(B)=0.02, p=0.76$ ), suggesting that mothers' anxiety was not driving childcentered behaviors. Neither maternal child-centered parenting $(B=-0.04, \operatorname{SE}(B)=0.04, p=$ $0.24)$ nor adoptive mother anxiety $(B=0.01, \mathrm{SE}(B)=0.01, p=0.45)$ predicted children's social inhibition at 18 months of age, suggesting the absence of additional environmental effects on longitudinal levels of inhibition. Similarly, the interaction between maternal childcentered parenting and birth parent anxiety did not significantly predict social inhibition at 18 months $(B=0.00, \operatorname{SE}(B)=0.00, p=0.53)$. 
Paternal child-centered parenting-In the model for adoptive fathers (Table 4), associations among control variables were largely similar to those found in the model for adoptive mothers. Analyses including primary study variables showed that, in contrast to findings for adoptive mothers, there was not evidence for evocative effects on paternal childcentered parenting behaviors. Neither birth parent anxiety $(B=0.00, \operatorname{SE}(B)=0.01, p=$ $0.99)$, nor social inhibition in children at 9 months of age $(B=-0.01, \operatorname{SE}(B)=0.08, p=$ $0.90)$ was associated with child centered parenting behaviors in adoptive fathers.

Adoptive father anxiety was not associated with levels of child-centered parenting ( $B=$ $-0.02, \operatorname{SE}(B)=0.03, p=0.40$ ), suggesting that paternal anxiety did not significantly influence the use of child-centered behaviors. Neither paternal child-centered parenting ( $B=$ $-0.01, \operatorname{SE}(B)=0.03, p=0.75)$ nor adoptive father anxiety $(B=0.02, \operatorname{SE}(B)=0.02, p=$ $0.22)$ predicted levels of children's social inhibition at 18 months of age. However, social inhibition at 18 months was significantly predicted by an interaction between birth parent anxiety and child-centered behaviors in adoptive fathers $(B=0.01, \operatorname{SE}(B)=0.00, p=0.01)$.

Following the suggestions of Aiken and West (1991), this interaction was probed by examining the simple slope of child-centered parenting at low $(-1 S D)$ and high $(+1 S D)$ levels of birth parent anxiety symptoms. Examining the interaction in this manner revealed that when birth parent anxiety symptoms were low, greater child-centered behavior in adoptive fathers at 9 months of age was related to less social inhibition in children at 18 months $(B=-0.10, S E(B)=0.04, p=0.02)$. In contrast, when birth parent anxiety symptoms were high, greater child-centered behavior in adoptive fathers at 9 months of age was marginally associated with greater social inhibition in children at age 18 months ( $B=$ $0.08, S E(B)=0.05, p=0.07$ ). Noting that a probe at high levels of birth parent anxiety corresponded to only moderate levels of birth parent risk, we added an additional probe at $+2 S D$, which corresponded to severe levels of anxiety in birth parents. Consistent with expectations for a standard distribution, roughly $6 \%$ of birth mothers $(n=31$ of 497$)$ and $3.5 \%$ ( $n=6$ of 170) of birth fathers with available data had BAI scores that met or exceeded the threshold for severe anxiety. This additional test revealed a positive association between child-centered behaviors in adoptive fathers and children's social inhibition at age 18 months $(B=0.16, S E(B)=0.06, p=0.01)$.

As a final probe of the interaction, we tested for regions of significance for the pattern of results reported above. The regions of significance testing procedure described by Hayes and Matthes (2009) uses the Johnson-Neyman technique to mathematically derive the point(s) along the range of the moderator variable (birth parent anxiety) where a focal predictor (child-focused parenting) transitions between statistical significance and nonsignificance based on the critical $t$ value associated with a $(p<.05)$. This analysis identified a significant $(p<.05)$ negative association between child-focused parenting and social inhibition when birth parents reported levels of anxiety below $7.47(B=-0.06, S E(B)=0.03, p=0.05)$. In contrast, paternal child-focused parenting was positively associated with social inhibition ( $p$ $<.05)$ when birth parents reported levels of anxiety greater than $32.90(B=0.17, S E(B)=$ $0.09, p=0.05)$. 
Multi-group Analysis-In order to test the significance of apparent differences in findings for adoptive mothers and fathers, a final model was examined that constrained each of the estimated paths in the final model to be equal across groups. This analysis tested whether the apparent differences in the findings for adoptive mothers and fathers were statistically significant. Overall fit was not significantly decreased in the constrained model ( $\Delta d f=35, \Delta X^{2}=37.83, p>.10$ ), suggesting that the size of the moderated effect did not differ for adoptive mothers and fathers.

\section{Discussion}

We found that inherited influences on risk for anxiety problems moderated the link between child-centered behaviors in infancy and social inhibition in toddlerhood for adoptive fathers but not adoptive mothers. When birth parent anxiety was low, indicating putatively low levels of inherited risk, more paternal child-centered behaviors during infancy predicted less social inhibition during toddlerhood. This finding is consistent with traditional ideas about the acquisition of self-regulation; specifically, this pattern of results suggests that paternal interventions on behalf of an infant can not only aid in the regulation of distress, but may also provide opportunities to foster the child's ability to regulate independently and promote healthy development (Kopp, 1982).

In contrast, when birth parent anxiety was high, indicating putatively high (i.e., severe) levels of inherited risk for anxiety problems, more paternal child-centered behaviors during infancy predicted greater social inhibition at 18 months of age. This pattern of results supports previous suggestions that parental behaviors frequently viewed as sensitive or protective may be detrimental under certain conditions. For example, parents who can readily anticipate the conditions under which children will become distressed may be more likely to employ protective parenting behaviors (Kiel \& Buss, 2011; Rubin \& Burgess, 2001). Although potentially effective at regulating short-term distress, frequent parental interventions may deprive children of opportunities to practice and fully develop selfregulatory skills (Arcus et al., 1992; Kopp, 1982). Consistent with this, greater accuracy in predicting distress is associated both with greater numbers of protective behaviors and greater social inhibition in children over time (Kiel \& Buss, 2011).

Child-based differences in the direction of the association between child-centered behaviors and social inhibition reflects a goodness-of-fit mechanism of gene-environment interaction (Reiss et al., 2013). While such a pattern is consistent with expectations for child-centered parenting and social inhibition based on the extant literature, it is important to note that this pattern is not observed for parenting and child adjustment more broadly. For example, previous work in this sample has shown that more structured parenting is associated with fewer behavior problems for children whose birth parents reported higher levels of mental health problems (Leve et al., 2009). In contrast, responsive parenting appeared to serve as a protective factor against the development of social wariness for children whose biological mothers met diagnostic criteria for social phobia (Natsuaki et al., 2013). It will be important for future work to identify the levels at which discrete parenting behaviors shift from being adaptive to potentially harmful based on child characteristics. 
Although our multi-group test suggested that the size of the moderated effect did not differ for mothers and fathers, overall patterns of effects were unique in the maternal and paternal models. Why might some mechanisms of fit differ for mothers relative to fathers? There is evidence that fathers are involved with their children in ways that are distinct from mothers (Fitzgerald, 1977, Labrell, 1994; Parke, 1996). Specifically, paternal behaviors appear to present greater numbers of expectancy violations for young children, which require children to negotiate novelty and ambiguity in the early social environment (Labrell, 1994). Fathers also spend more time in physical play (e.g., bouncing, lifting) with infants relative to mothers (Power \& Parke, 1982). Paternal tendencies to engage in idiosyncratic play activities make important and unique contributions to children's early development (Lamb \& Lewis, 2010; 2013), while mothers initiate similar cognitive and physical challenges in other ways. Thus, neither a paternal nor maternal approach is obviously superior, but the two might be viewed as qualitatively distinct (Parke, 1996).

Indeed paternal behaviors have been shown to predict child outcomes independently from maternal behaviors, underscoring the uniqueness rather than overlap of these constructs. Retrospective reports of parenting suggest that levels of paternal affection and discipline during childhood moderate influences on adult internalizing symptoms (South \& Jarnecke, 2015). Paternal sensitive parenting during infancy also contributes to aspects of children's self-regulation independent from maternal behaviors (Towe-Goodman et al., 2014), although this influence appeared not to extend beyond toddlerhood. Relatively recent research also suggests that fathers' pre- and postnatal depressive symptoms predict early and middle childhood psychopathology independently of maternal symptoms (Ramchandani et al., 2008). Thus, fathers appear to make unique contributions to children's early socioemotional development. Heightened exposure to paternal symptoms and parenting behaviors may be independent influences, operating through unique pathways, on children's mental health.

Paternal behaviors likely impact child outcomes through perturbations of biological systems linked to self-regulation. Similar to the current study, Hastings (2008) and colleagues found that the impact of fathers', but not mothers', parenting on children's anxious behaviors was dependent on biologically-based processes of regulation. Researchers speculated on the possibility that a pattern of direct effects for maternal behaviors but moderated effects for fathers may result from differences in interactions with caregivers. Specifically, they postulated that interactions with fathers may be more context-specific and thereby subject to greater influence from child-based factors that impact state regulation. Our findings, which also show direct associations between maternal parenting and both birth parent anxiety and concurrent wariness in children, support the idea that mothers are responsive to children's characteristics. This conclusion is tentative based on our inability to determine the direction of effects for contemporaneous measures, but are in line with prior notions that maternal and paternal behaviors operate through distinct mechanisms in association with child outcomes.

An alternative possibility is that differences in patterns of effects for mothers and fathers reflect differences in primary and secondary caregiver roles rather than differences in maternal and paternal behaviors per se. Paternal involvement in childcare continues to increase (Lamb \& Lewis, 2010), with roughly $20 \%$ of fathers reporting roles as primary caregivers for their children in 2011 (U.S. Census, 2011). Recent research has suggested that 
patterns of neural activity in caregivers reflect roles as primary and secondary caregivers rather than roles as mothers and fathers (Abraham et al., 2014). The number of fathers serving as primary caregivers in the current sample is small, limiting power to test this possibility directly. However, this will be important to keep in mind in the interpretation of our results and in the planning of future research.

We did not observe any evidence for direct heritable effects of birth parent anxiety on children's social inhibition. Direct heritable effects linking parent symptoms to early anxious behaviors in children, measured through an assessment of parent-reported symptoms, are similarly absent from past reports (Brooker et al., 2011; Natsuaki et al., 2013). However, anxious behaviors in parents have been directly associated with levels of anxiety risk in infants (Aktar et al., 2013; McClure, Brennan, Hammen, \& Le Brocque, 2001). This suggests that assessments of discrete behaviors may be most informative for deriving levels of early risk for anxiety problems.

Finally, in a set of exploratory analyses, we found evidence for associations between prenatal risk and both child and parent behaviors. Birth parents' reports of pregnancy complications were positively associated with both birth parent anxiety symptoms and levels of social inhibition in toddlers. As direct associations between birth mother anxiety and pregnancy complications have not been consistently observed (Beck et al., 1980; Perkin, Bland, Peacock, \& Anderson, 1993), it may be the case that obstetric complications reflect a mechanism by which maternal anxiety leads to more negative outcomes in infants.

Nonetheless, it will be critical for future research to test the degree to which other parentand child-based factors may moderate such an association.

\section{Limitations}

The current study may be limited in the generalizability of conclusions made regarding low levels of child-centered behaviors on the development of behavioral inhibition. Given the screenings that are in place for parents who wish to adopt, it is unlikely that the lowest levels of child-centered parenting would have been observed in our sample. In fact, one might expect that extremely low levels of child-centered behavior would be detrimental for all infants. It will be important for future work to include parents reflecting the full spectrum of child-centered behaviors. Generalizability may also be limited if levels of anxiety differ for birth parents who do (versus do not) choose to put their children up for adoption. That is, if birth parents who choose to put their child up for adoption are generally more anxious than birth parents who do not make this decision, our sample may be relatively high risk in nature. Additional data from a sample of birth parents matched on demographic and other key variables would be needed to say definitively if this is the case.

The current work also does not specify the mechanism by which child-centered behaviors in parents play a role in the development of social inhibition. Although many of the studies discussed above implicate a role for self-regulatory skills, such behaviors were not included in the current work. Elucidating the mechanisms through which parent behaviors come to impact child outcomes will be critical for advancing childhood programs of prevention and intervention. 
Third, although tasks were selected to be equal in task difficulty, mothers and fathers did not complete the same tasks with their child. This element of the study was necessary in order to eliminate within-child practice effects. However, it does introduce the possibility that, if one task was more difficult, it may have led to mean level differences in parenting behaviors as reported in the current study. If such differences also led to restricted variability in childcentered parenting for mothers, they may further explain the nonsignificant interaction between mothers' child-centered parenting and birth parent anxiety. We are reassured that roughly equivalent levels of variability are observed for parenting behaviors in our data. However, task differences reflect a potential limitation of the current work.

Fourth, our study did not directly assess the proportion of time or types of activities in which adoptive fathers were typically engaged with their infant. Previous studies have suggested that fathers may affect child outcomes through both direct mechanisms - such as face-toface interactions - and indirect mechanisms - such as via fathers' interactions with mothers (Parke, 1996). Thus, it is difficult to derive a quantitative measure of the degree to which fathers may have the potential to influence child outcomes. It will be of value for future research to characterize the quantity and quality of "typical" father-infant interactions with infants in order to further understand the effects reported here.

Finally, although this work is unique in its inclusion of data from both birth mothers and birth fathers, there was a high proportion of missing data from birth fathers. Thus, it is possible that heritable liabilities most fully reflect maternal-based characteristics in the sample as a whole. Further work that includes equal proportions of data from birth mothers and birth fathers will be necessary to determine more fully capture heritable risk.

\section{Conclusions}

Furthermore, our results underscore previous assertions that "fit" between child-based characteristics and the early environment is a critical factor in shaping child outcomes from very early in life. Specifically, we used a genetically-informative design to show that heritable characteristics in children moderated the association between paternal childcentered parenting during infancy and levels of social inhibition during toddlerhood. This work offers evidence that inherited factors may be important to consider in work that investigates the effects of parent behaviors and child outcomes, particularly examinations of early risk for anxiety problems in the form of social inhibition.

\section{Acknowledgments}

Data collection for this project was supported by R01 HD042608; NICHD, NIDA, and OBSSR; NIH; U.S. PHS (PI Years 1-5: Reiss; PI Years 6-10: Leve). The writing of this manuscript was partially supported by R01 DA020585, NIDA, NIMH, and OBSSR; NIH; U.S. PHS (PI: Neiderhiser), K01 MH100240 (PI: Brooker), P20 GM104417 (PI: Harmsen), F31 DA033737 (PI: Marceau), K01 DA039288 (PI: Marceau) and T32 MH019927 (PI: Spirito). The content is solely the responsibility of the authors and does not necessarily represent the official views of the National Institutes of Health.

We thank the families that participated in this study and the adoption agency staff members who helped with the recruitment of study participants. 


\section{References}

Abraham E, Hendler T, Shapira-Lichter I, Kanat-Maymon Y, Zagoory-Sharon O, Feldman R. Father's brain is sensitive to childcare experiences. Proceedings of the National Academy of Sciences. 2014; 111(27):9792-9797. http://doi.org/10.1073/pnas.1402569111.

Aiken, LS.; West, SG. Multiple regression: Testing and interpreting interactions. Thousand Oaks, CA: Sage Publications; 1991.

Aktar E, Majdandžić M, de Vente W, Bögels SM. The interplay between expressed parental anxiety and infant behavioural inhibition predicts infant avoidance in a social referencing paradigm. Journal of Child Psychology and Psychiatry. 2013; 54(2):144-156. http://doi.org/10.1111/j. 1469-7610.2012.02601.x. [PubMed: 22924437]

Arcus, DM.; Gardner, S.; Anderson, C. Temperament and environment. Miami: 1992. Infant reactivity, maternal style, and the development of inhibited and uninhibited behavioral profiles.

Beck, AT.; Steer, RA. Beck depression inventory manual. San Antonio: The Psychological Corporation: Harcourt Brace Jovanovich; 1993.

Beck NC, Siegel LJ, Davidson NP, Kormeier S, Breitenstein A, Hall DG. The prediction of pregnancy outcome: Maternal preparation, anxiety and attitudinal sets. Journal of Psychosomatic Research. 1980; 24(6):343-351. http://doi.org/10.1016/0022-3999(80)90026-4. [PubMed: 7205723]

Bell RQ. A Reinterpretation of the direction of effects in studies of socialization. Psychological Review. 1968; 75(2):81-95. [PubMed: 4870552]

Belsky J, Pluess M. Beyond diathesis stress: Differential susceptibility to environmental influences. Psychological Bulletin. 2009; 135(6):885-908. http://doi.org/10.1037/a0017376. [PubMed: 19883141]

Biederman J, Hirshfeld-Becker DR, Rosenbaum JF, Herot C, Friedman D, Snidman N, ... Faraone SV. Further evidence of association between behavioral inhibition and social anxiety in children. American Journal of Psychiatry. 2001; 158(10):1673-1679. http://doi.org/10.1176/appi.ajp. 158.10.1673. [PubMed: 11579001]

Bluestone C, Tamis-LeMonda CS. Correlates of Parenting Styles in Predominantly Working- and Middle-Class African American Mothers. Journal of Marriage and Family. 1999; 61(4):881-893. http://doi.org/10.2307/354010.

Boyce WT, Ellis BJ. Biological sensitivity to context: I. An evolutionary-developmental theory of the origins and functions of stress reactivity. Development and Psychopathology. 2005; 17:271-301. http://doi.org/10.1017/S0954579405050145. [PubMed: 16761546]

Bronfenbrenner, U. The ecology of human development: Experiments by nature and design. Cambridge, MA: Harvard University Press; 1979.

Brooker RJ, Buss KA, Lemery-Chalfant K, Aksan N, Davidson RJ, Goldsmith HH. The development of stranger fear in infancy and toddlerhood: Normative development, individual differences, antecedents, and outcomes. Developmental Science. 2013; 16(6):864-878. http://doi.org/10.1111/ desc.12058. [PubMed: 24118713]

Brooker RJ, Kiel EJ, Buss KA. Profiles of developing social and object fear in toddlerhood: Moderation by inhibitory control and associations with anxious behaviors in kindergarten. Emotion. in press.

Brooker RJ, Neiderhiser JM, Kiel EJ, Leve LD, Shaw DS, Reiss D. The association between infants' attention control and social inhibition is moderated by genetic and environmental risk for anxiety. Infancy. 2011; 16(5):490-507. http://doi.org/10.1111/j.1532-7078.2011.00068.x. [PubMed: 21857796]

Buss KA, McDoniel ME. Improving the Prediction of Risk for Anxiety Development in Temperamentally Fearful Children. Current Directions in Psychological Science. 2016; 25(1):1420. http://doi.org/10.1177/0963721415611601. [PubMed: 27134416]

Chess, S.; Thomas, A. Temperament and development. New York: 1977.

Chronis-Tuscano A, Degnan KA, Pine DS, Perez-Edgar K, Henderson HA, Diaz Y, ... Fox NA. Stable early maternal report of behavioral inhibition predicts lifetime social anxiety disorder in adolescence. Journal of the American Academy of Child and Adolescent Psychiatry. 2009; 48(9): 928-935. http://doi.org/10.1097/CHI.0b013e3181ae09df. [PubMed: 19625982] 
Cicchetti, D.; Cohen, DJ. Developmental Psychopathology, Developmental Neuroscience. John Wiley \& Sons; 2006.

Clauss JA, Blackford JU. Behavioral inhibition and risk for developing social anxiety disorder: A meta-analytic study. Journal of the American Academy of Child \& Adolescent Psychiatry. 2012; 51(10):1066-1075. e1. http://doi.org/10.1016/j.jaac.2012.08.002. [PubMed: 23021481]

Crockenberg SC, Leerkes EM. Infant and maternal behaviors regulate infant reactivity to novelty at 6 months. Developmental Psychology. 2004; 40(6):1123-1132. http://doi.org/ 10.1037/0012-1649.40.6.1123. [PubMed: 15535761]

Crockenberg SC, Leerkes EM. Infant and maternal behavior moderate reactivity to novelty to predict anxious behavior at 2.5 years. Development and Psychopathology. 2006; 18:17-34. http://doi.org/ 10.1017/S0954579406060020. [PubMed: 16478550]

Davidov M, Knafo-Noam A, Serbin LA, Moss E. The influential child: How children affect their environment and influence their own risk and resilience. Development and Psychopathology. 2015; 27(4pt1):947-951. http://doi.org/10.1017/S0954579415000619. [PubMed: 26439055]

Degnan KA, Almas AN, Henderson HA, Hane AA, Walker OL, Fox NA. Longitudinal trajectories of social reticence with unfamiliar peers across early childhood. Developmental Psychology. 2014; 50(10):2311-2323. http://doi.org/10.1037/a0037751. [PubMed: 25181648]

Degnan KA, Henderson HA, Fox NA, Rubin KH. Predicting social wariness in middle childhood: The moderating roles of childcare history, maternal personality and maternal behavior. Social Development. 2008; 17(3):471-487. http://doi.org/10.1111/j.1467-9507.2007.00437.x. [PubMed: 20463856]

Dierker LC, Merikangas KR, Szatmari P. Influence of parental concordance for psychiatric disorders on psychopathology in offspring. Journal of the American Academy of Child \& Adolescent Psychiatry. 1999; 38(3):280-288. http://doi.org/10.1097/00004583-199903000-00015. [PubMed: 10087689]

Dogan, S.; Lei, A.; Milne-Kahn, J.; Pong, H.; Wu, E.; Conger, R. Family interaction beahvioral codes for the Early Growth and Development Study. 2005. Unpublsihed coding manual

Enders, C. Applied missing data analysis. New York: The Guilford Press; 2010.

Fitzgerald, HE. Infants and caregivers: Sex differences as determinants of socialization. In: Donelson, E.; Gullahorn, J., editors. Women: A psychological perspective. New York, New York: Wiley; 1977.

Goldsmith HH, Buss AH, Plomin R, Rothbart MK, Thomas A, Chess S, .. McCall RB. Roundtable: What is temperament? Four approaches. Child Development. 1987; 58(2):505-529. http://doi.org/ 10.2307/1130527. [PubMed: 3829791]

Goldsmith HH, Lemery KS, Buss KA, Campos JJ. Genetic analyses of focal aspects of infant temperament. Developmental Psychology. 1999; 35(4):972-985. http://doi.org/ 10.1037/0012-1649.35.4.972. [PubMed: 10442866]

Grotevant HD, McRoy RG, Elde CL, Fravel DL. Adoptive Family System Dynamics: Variations by Level of Openness in the Adoption. Family Process. 1994; 33(2):125-146. http://doi.org/10.1111/j. 1545-5300.1994.00125.x. [PubMed: 7925924]

Hayes A, Matthes J. Computational procedures for probing interactions in OLS and logistic regression: SPSS and SAS implementations. Behavior Research Methods. 2009; 41(3):924-936. http:// doi.org/10.3758/BRM.41.3.924. [PubMed: 19587209]

Hirshfeld-Becker DR, Biederman J, Henin A, Faraone SV, Davis S, Harrington K, Rosen JF. Behavioral inhibition in preschool children at risk is a specific predictor of middle childhood social anxiety: A five-year follow-up. Journal of Developmental \& Behavioral Pediatrics. 2007; 28(3):225-233. [PubMed: 17565290]

Hirshfeld DR, Rosenbaum JF, Biederman J, Bolduc EA, Faraone SV, Snidman N, ... Kagan J. Stable behavioral inhibition and its association with anxiety disorder. Journal of the American Academy of Child and Adolescent Psychiatry. 1992; 31(1):103-111. [PubMed: 1537760]

Hoff, E.; Laursen, B.; Tardif, T. Socioeconomic status and parenting. In: Bornstein, MH., editor. Handbook of Parenting. 2. Vol. 2. Mahwah, NJ: Lawrence Erlbaum Associates; 2002. p. 231-252.Biology and ecology of parenting 
Hudson JL, Comer JS, Kendall PC. Parental Responses to Positive and Negative Emotions in Anxious and Nonanxious Children. Journal of Clinical Child \& Adolescent Psychology. 2008; 37(2):303313. http://doi.org/10.1080/15374410801955839. [PubMed: 18470768]

Kagan, J. The nature of the child. New York, New York: Basic Books; 1984.

Kagan, J. Galen's prophecy: Temperament in human nature. New York, New York: Basic Books; 1994.

Kiel E, Buss K. Prospective relations among fearful temperament, protective parenting, and social withdrawal: The role of maternal accuracy in a moderated mediation framework. Journal of Abnormal Child Psychology. 2011; 39(7):953-966. http://doi.org/10.1007/s10802-011-9516-4. [PubMed: 21537895]

Kiel EJ, Maack DJ. Maternal BIS sensitivity, overprotective parenting, and children's internalizing behaviors. Personality and Individual Differences. 2012; 53(3):257-262. http://doi.org/10.1016/ j.paid.2012.03.026. [PubMed: 22904590]

Kochanska G. Patterns of inhibition to the unfamiliar in children of normal and affectively ill mothers. Child Development. 1991; 62(2):250-263. http://doi.org/10.1111/j.1467-8624.1991.tb01529.x. [PubMed: 2055122]

Kopp CB. Antecedents of self-regulation: A developmental perspective. Developmental Psychology. 1982; 18(2):199-214.

Labrell F. A typical interaction behaviour between fathers and toddlers: Teasing. Early Development and Parenting. 1994; 3(2):125-130. http://doi.org/10.1002/edp.2430030209.

Lamb, ME.; Lewis, C. The development and significance of father-child relationships in two-parent families. In: Lamb, ME., editor. The role of the father in child development. 4. Chichester, UK: Wiley; 2010. p. 94-153.

Lamb, ME.; Lewis, C. Father-child relationships. In: Cabrera, NJ.; Tamis-LeMonda, CS., editors. Handbook of Father Involvement. 2. New York: Routledge; 2013. p. 119-134.

Leve LD, Harold GT, Ge X, Neiderhiser JM, Shaw D, Scaramella LV, Reiss D. Structured parenting of toddlers at high versus low genetic risk: Two pathways to child problems. Journal of the American Academy of Child \& Adolescent Psychiatry. 2009; 48(11):1102-1109. http://doi.org/10.1097/CHI. 0b013e3181b8bfc0. [PubMed: 19797981]

Leve LD, Neiderhiser JM, Shaw DS, Ganiban J, Natsuaki MN, Reiss D. The Early Growth and Development Study: A prospective adoption study from birth through middle childhood. Twin Research and Human Genetics. 2013; 16(Special Issue 01):412-423. http://doi.org/10.1017/thg. 2012.126. [PubMed: 23218244]

Lucassen N, Tharner A, Van IJzendoorn MH, Bakermans-Kranenburg MJ, Volling BL, Verhulst FC, ... Tiemeier $\mathrm{H}$. The association between paternal sensitivity and infant-father attachment security: A meta-analysis of three decades of research. Journal of Family Psychology. 2011; 25(6):986-992. http://doi.org/10.1037/a0025855. [PubMed: 22004434]

Lytton H, Romney DM. Parents' differential socialization of boys and girls: A meta-analysis. Psychological Bulletin. 1991; 109(2):267-296. http://doi.org/10.1037/0033-2909.109.2.267.

Marceau K, Hajal N, Leve LD, Reiss D, Shaw DS, Ganiban JM, ... Neiderhiser JM. Measurement and associations of pregnancy risk factors with genetic influences, postnatal environmental influences, and toddler behavior. International Journal of Behavioral Development. 2013; 37(4):366-375. http://doi.org/10.1177/0165025413489378. [PubMed: 24839336]

Matheny AP. Children's behavioral inhibition over age and across situations: Genetic similarity for a trait during change. Journal of Personality. 1989; 57(2):215-235. http://doi.org/10.1111/j. 1467-6494.1989.tb00481.x. [PubMed: 2769555]

Mattson SN, Riley EP. Parent ratings of behavior in children with heavy prenatal alcohol exposure and IQ-matched controls. Alcoholism: Clinical and Experimental Research. 2000; 24(2):226-231. http://doi.org/10.1111/j.1530-0277.2000.tb04595.x.

McClure E, Brennan P, Hammen C, Le Brocque R. Parental anxiety disorders, child anxiety disorders, and the perceived parent-child relationship in an Australian high-risk sample. Journal of Abnormal Child Psychology. 2001; 29(1):1-10. http://doi.org/10.1023/A:1005260311313. [PubMed: 11316331]

Mill J, Petronis A. Pre- and peri-natal environmental risks for attention-deficit hyperactivity disorder (ADHD): the potential role of epigenetic processes in mediating susceptibility. Journal of Child 
Psychology and Psychiatry. 2008; 49(10):1020-1030. http://doi.org/10.1111/j. 1469-7610.2008.01909.x. [PubMed: 18492038]

Moore PS, Whaley SE, Sigman M. Interactions between mothers and children: Impacts of maternal and child anxiety. Journal of Abnormal Psychology. 2004; 113(3):471-476. http://doi.org/ 10.1037/0021-843X.113.3.471. [PubMed: 15311992]

Mount KS, Crockenberg SC, Bárrig Jó PS, Wagar JL. Maternal and child correlates of anxiety in 21/2year-old children. Infant Behavior and Development. 2010; 33(4):567-578. http://doi.org/10.1016/ j.infbeh.2010.07.008. [PubMed: 20723999]

Natsuaki MN, Leve LD, Neiderhiser JM, Shaw DS, Scaramella LV, Ge X, Reiss D. Intergenerational transmission of risk for social inhibition: The interplay between parental responsiveness and genetic influences. Development and Psychopathology. 2013; 25(Special Issue 01):261-274. http://doi.org/10.1017/S0954579412001010. [PubMed: 23398764]

Parke, RD. Fatherhood. Cambridge, MA: Harvard University Press; 1996.

Park SY, Belsky J, Putnam S, Crnic K. Infant emotionality, parenting, and 3-year inhibition: Exploring stability and lawful discontinuity in a male sample. Developmental Psychology. 1997; 33(2):218227. [PubMed: 9147831]

Perkin MR, Bland JM, Peacock JL, Anderson HR. The effect of anxiety and depression during pregnancy on obstetric complications. BJOG: An International Journal of Obstetrics \& Gynaecology. 1993; 100(7):629-634. http://doi.org/10.1111/j.1471-0528.1993.tb14228.x.

Plomin, R. Development, genetics, and psychology. Hillsdale, NJ: Erlbaum; 1986.

Power, TG.; Parke, RD. Play as a Context for Early Learning. In: Laosa, LM.; Sigel, IE., editors. Families as Learning Environments for Children. Boston, MA: Springer US; 1982. p. 147-178.Retrieved from http://dx.doi.org/10.1007/978-1-4684-4172-7_5

Prior M, Smart D, Sanson A, Oberklaid F. Does shy-inhibited temperament in childhood lead to anxiety problems in adolescence? Journal of the American Academy of Child \& Adolescent Psychiatry. 2000; 39(4):461-468. http://doi.org/10.1097/00004583-200004000-00015. [PubMed: 10761348]

Ramchandani PG, O'Connor TG, Evans J, Heron J, Murray L, Stein A. The effects of pre and postnatal depression in fathers: a natural experiment comparing the effects of exposure to depression on offspring. Journal of Child Psychology and Psychiatry. 2008; 49(10):1069-1078. [PubMed: 19017023]

Reiss D, Leve LD, Neiderhiser JM. How genes and the social environment moderate each other. American Journal of Public Health. 2013; 103(S1):S111-S121. http://doi.org/10.2105/AJPH. 2013.301408. [PubMed: 23927504]

Rubin, KH.; Burgess, KB. Social withdrawal and anxiety. In: Vasey, MW.; Dadds, MR., editors. The developmental psychopathology of anxiety. New York: Oxford University Press; 2001. p. 407-434.

South S, Jarnecke A. Genetic and Environmental Influences on Adult Mental Health: Evidence for Gene-Environment Interplay as a Function of Maternal and Paternal Discipline and Affection. Behavior Genetics. 2015; 45(4):438-450. http://doi.org/10.1007/s10519-015-9716-8. [PubMed: 25842345]

Stemberger RT, Turner SM, Beidel DC, Calhoun KS. Social phobia: An analysis of possible developmental factors. Journal of Abnormal Psychology. 1995; 104(3):526-531. http://doi.org/ 10.1037/0021-843X.104.3.526. [PubMed: 7673576]

Towe-Goodman NR, Willoughby M, Blair C, Gustafsson HC, Mills-Koonce WR, Cox MJ. Fathers' sensitive parenting and the development of early executive functioning. Journal of Family Psychology. 2014; 28(6):867-876. http://doi.org/10.1037/a0038128. [PubMed: 25347539]

Volbrecht MM, Goldsmith HH. Early temperamental and family predictors of shyness and anxiety. Developmental Psychology. 2010; 46(5):1192-1205. [PubMed: 20822232]

Warren SL, Simmens SJ. Predicting toddler anxiety/depressive symptoms: Effects of caregiver sensitivity on temperamentally vulnerable children. Infant Mental Health Journal. 2005; 26(1):40 55. http://doi.org/10.1002/imhj.20034. 


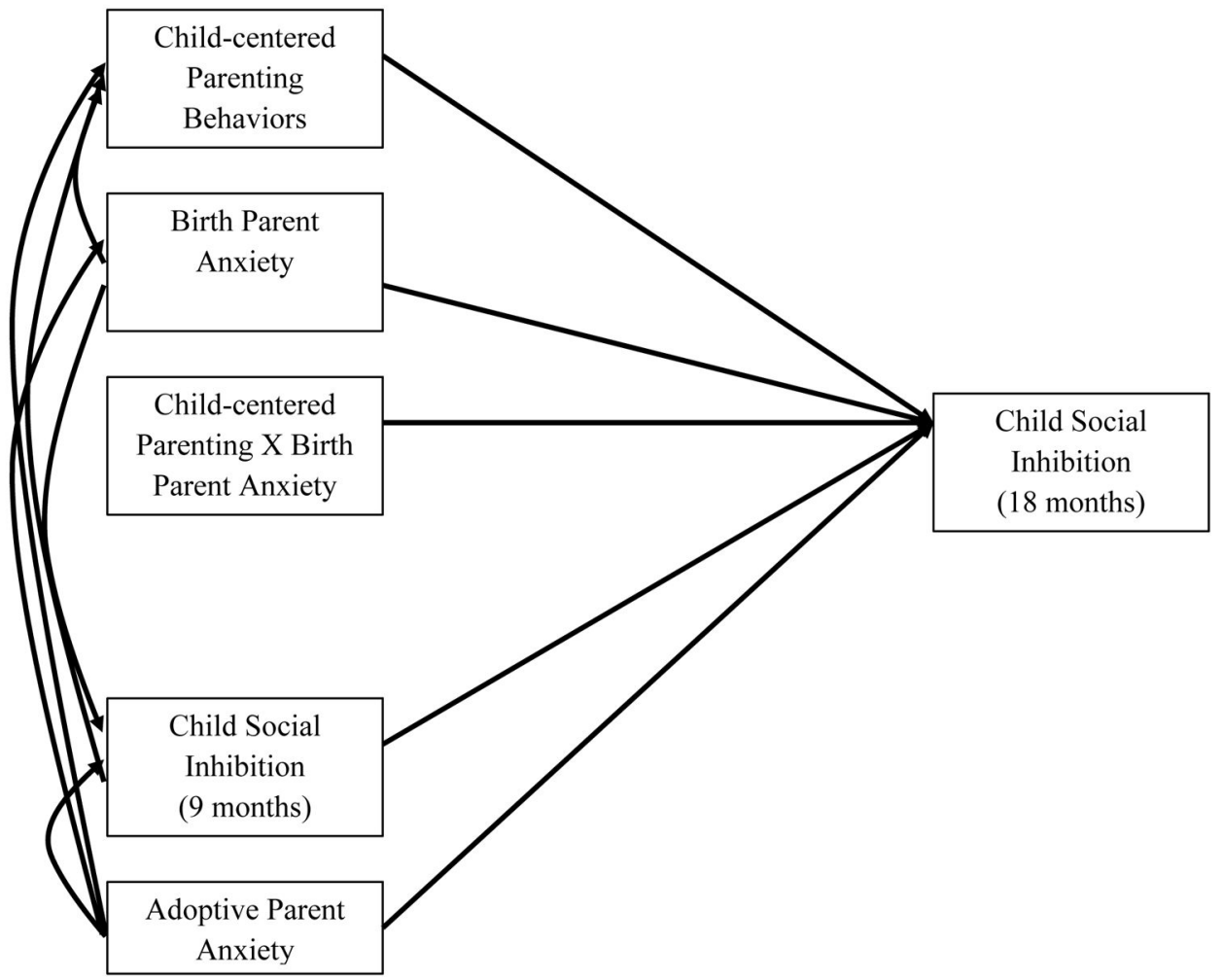

Figure 1. Full Model for Data Analysis

Note: Covariates included openness of adoption, sex of child, age at placement, adoptive parent level of education, and pregnancy complications. Covariates were regressed on every study variable depicted in the model (but were excluded from the figure for ease of interpretation). 


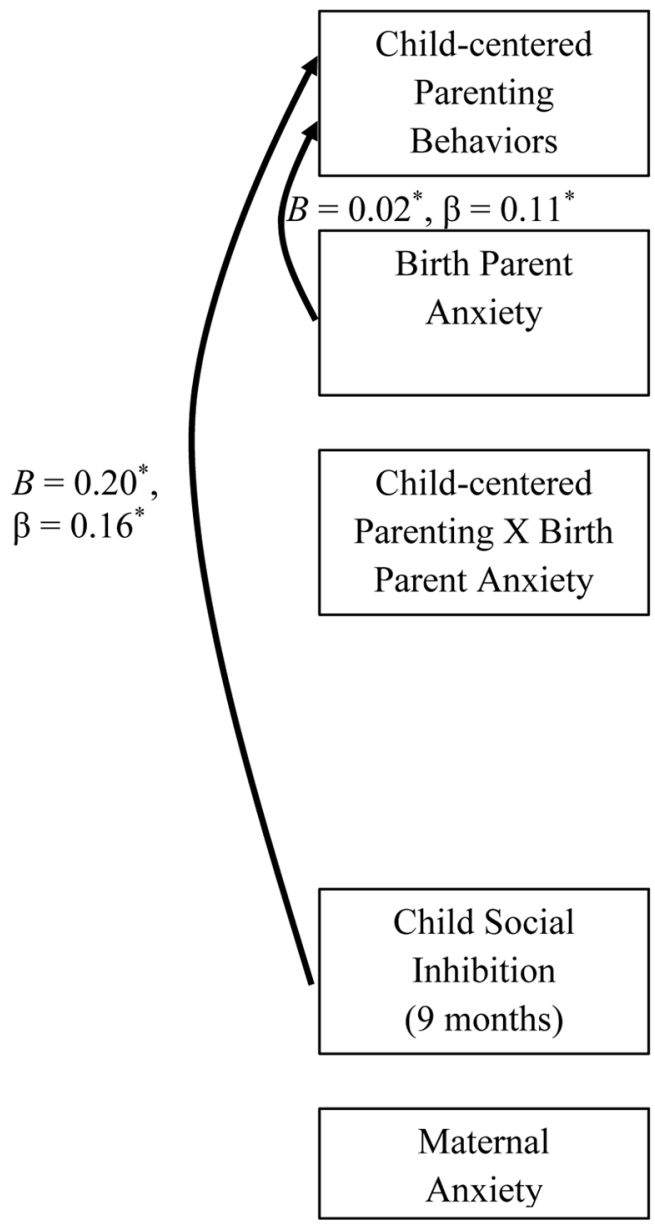

Figure 2. Maternal child-centered parenting and social inhibition

Note: $N=489$, RMSEA $=0.07$ [95\% CI: 0.04, 0.09], SRMR = 0.03. Nonsignificant paths are not shown. Solid lines are significant at $* p<0.05$. Control Covariates included openness of adoption, sex of child, age at placement, adoptive parent level of education, and pregnancy complications. Covariates were regressed on every study variable depicted in the model (but were excluded from the figure for ease of interpretation). 

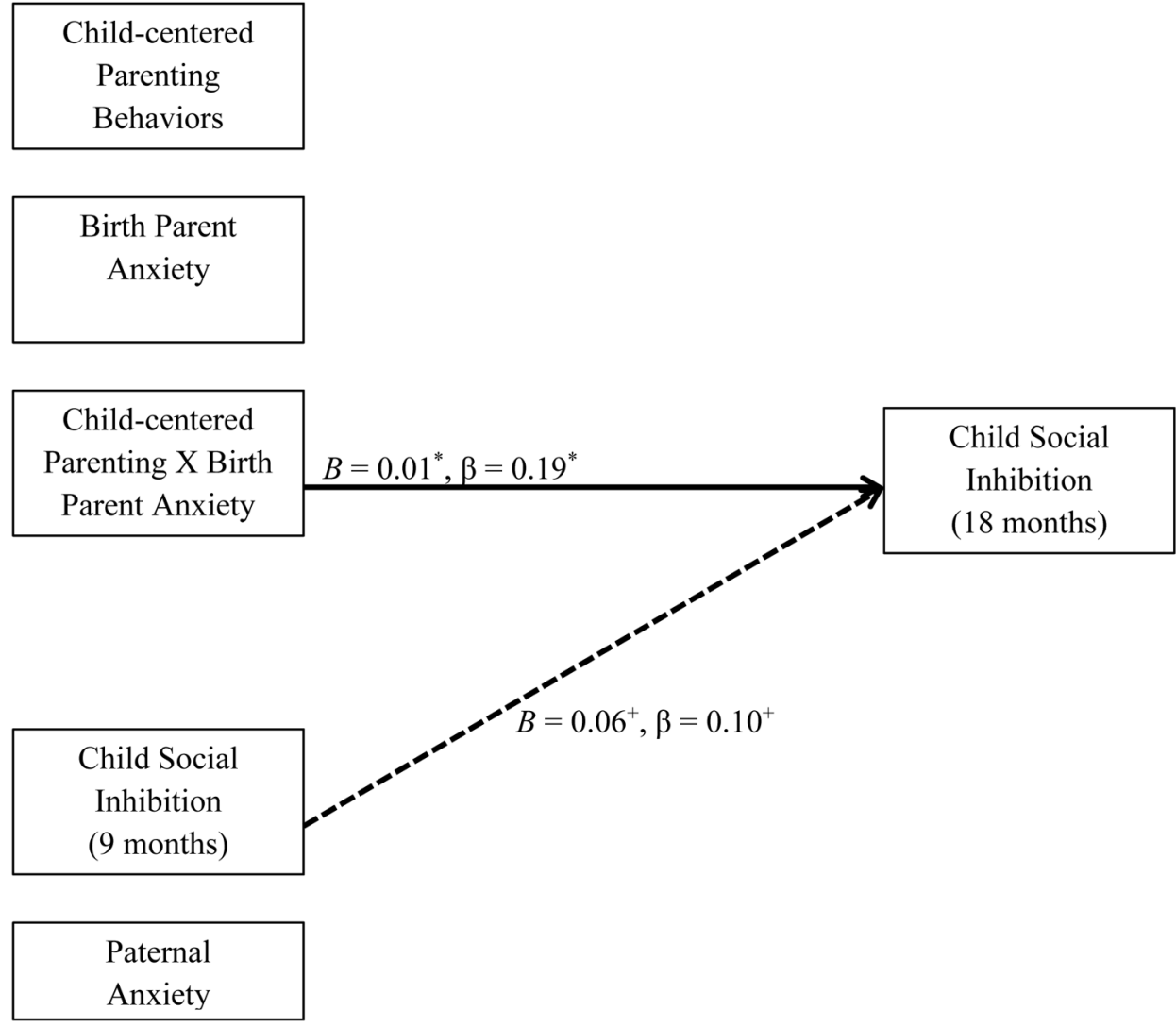

Figure 3. Paternal child-centered parenting and social inhibition

Note: $N=476$, RMSEA $=0.05$ [95\% CI: 0.02, 0.07], SRMR $=0.03$. Nonsignificant paths are not shown. Dashed lines are significant at $+p<0.10$, solid lines are significant at $* p<$ 0.05 . Covariates included openness of adoption, sex of child, age at placement, adoptive parent level of education, and pregnancy complications. Covariates were regressed on every study variable depicted in the model (but were excluded from the figure for ease of interpretation). 


\section{롤 \\ 골}
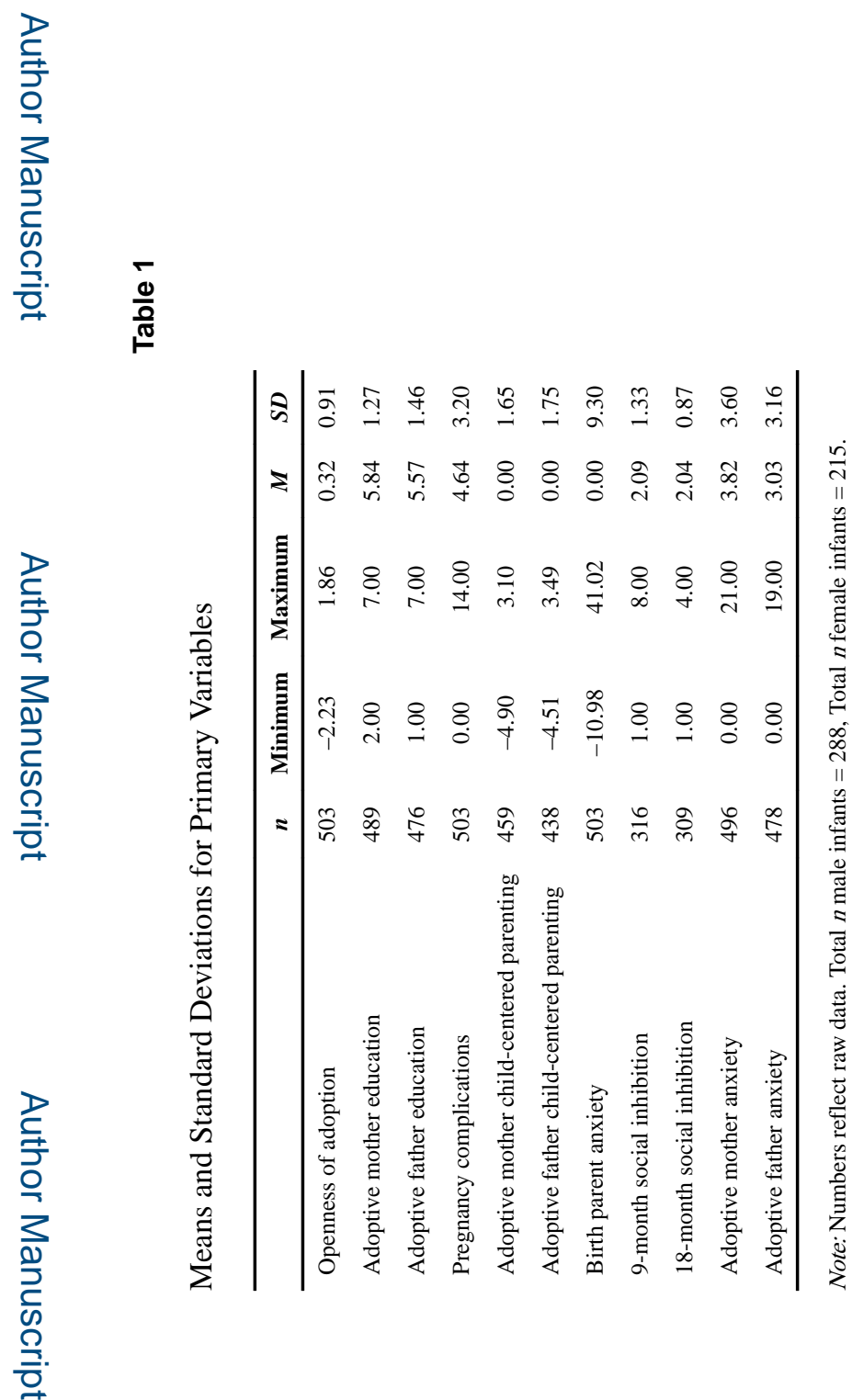

J Dev Orig Health Dis. Author manuscript; available in PMC 2017 December 01. 


\section{로을}

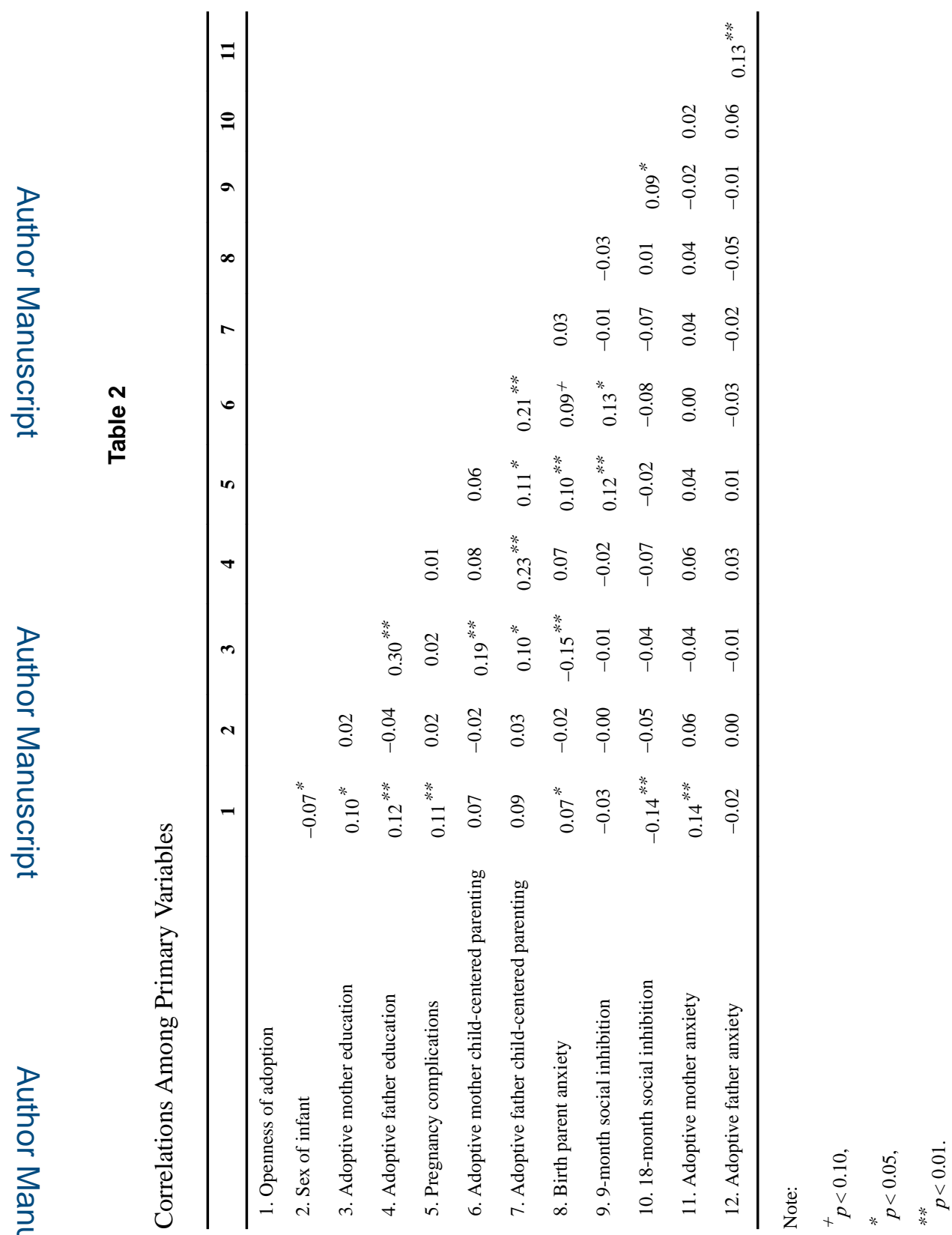


Table 3

Structural Equation Model Results for Primary Outcomes: Mothers

\begin{tabular}{|c|c|c|c|}
\hline & $\begin{array}{c}\text { Unstandardized } \\
B\end{array}$ & $\begin{array}{c}\text { Standardized } \\
\beta\end{array}$ & $p$ \\
\hline \multicolumn{4}{|l|}{ Outcome: 18-month social inhibition } \\
\hline \multicolumn{4}{|l|}{ Covariates: } \\
\hline Openness of Adoption & $-0.13(0.06)$ & $-0.14(0.06)$ & 0.02 \\
\hline Sex of Infant & $-0.11(0.10)$ & $-0.06(0.06)$ & 0.28 \\
\hline Adoptive Parent Education & $-0.01(0.04)$ & $-0.01(0.06)$ & 0.82 \\
\hline Pregnancy Complications & $-0.01(0.02)$ & $-0.02(0.06)$ & 0.70 \\
\hline \multicolumn{4}{|l|}{ Primary Variables: } \\
\hline Child-centered parenting & $-0.04(0.04)$ & $-0.08(0.07)$ & 0.24 \\
\hline Birth parent anxiety & $0.00(0.01)$ & $0.04(0.06)$ & 0.53 \\
\hline Child-centered parenting* Birth parent anxiety & $0.00(0.00)$ & $0.04(0.06)$ & 0.53 \\
\hline 9-month social inhibition & $0.05(0.04)$ & $0.08(0.06)$ & 0.16 \\
\hline Maternal anxiety & $0.01(0.01)$ & $0.04(0.06)$ & 0.45 \\
\hline \multicolumn{4}{|l|}{ Outcome: Child-centered parenting } \\
\hline \multicolumn{4}{|l|}{ Covariates: } \\
\hline Openness of Adoption & $0.08(0.09)$ & $0.04(0.05)$ & 0.37 \\
\hline Sex of Infant & $-0.09(0.15)$ & $-0.03(0.05)$ & 0.56 \\
\hline Adoptive Parent Education & $0.25(0.06)$ & $0.20(0.05)$ & $<0.01$ \\
\hline Pregnancy Complications & $0.01(0.02)$ & $0.02(0.05)$ & 0.66 \\
\hline \multicolumn{4}{|l|}{ Primary Variables: } \\
\hline Birth parent anxiety & $0.02(0.01)$ & $0.11(0.05)$ & 0.02 \\
\hline 9-month social inhibition & $0.20(0.08)$ & $0.16(0.06)$ & 0.01 \\
\hline Maternal anxiety & $0.01(0.02)$ & $0.02(0.05)$ & 0.76 \\
\hline \multicolumn{4}{|l|}{ Outcome: 9-month social inhibition } \\
\hline \multicolumn{4}{|l|}{ Covariates: } \\
\hline Openness of Adoption & $-0.05(0.09)$ & $-0.04(0.06)$ & 0.53 \\
\hline Sex of Infant & $-0.04(0.15)$ & $-0.01(0.06)$ & 0.82 \\
\hline Adoptive Parent Education & $-0.00(0.06)$ & $-0.00(0.06)$ & 0.99 \\
\hline Pregnancy Complications & $0.06(0.02)$ & $0.13(0.06)$ & 0.02 \\
\hline \multicolumn{4}{|l|}{ Primary Variables: } \\
\hline Birth parent anxiety & $-0.01(0.01)$ & $-0.04(0.06)$ & 0.49 \\
\hline Maternal anxiety & $-0.01(0.02)$ & $-0.01(0.06)$ & 0.81 \\
\hline \multicolumn{4}{|l|}{ Outcome: Maternal anxiety } \\
\hline \multicolumn{4}{|l|}{ Covariates: } \\
\hline Openness of Adoption & $0.59(0.18)$ & $0.15(0.05)$ & $<0.01$ \\
\hline Sex of Infant & $0.61(0.33)$ & $0.08(0.05)$ & 0.06 \\
\hline Adoptive Parent Education & $-0.15(0.13)$ & $-0.05(0.05)$ & 0.23 \\
\hline Pregnancy Complications & $0.02(0.05)$ & $0.02(0.05)$ & 0.63 \\
\hline
\end{tabular}

J Dev Orig Health Dis. Author manuscript; available in PMC 2017 December 01. 


\begin{tabular}{lccc}
\hline & $\begin{array}{c}\text { Unstandardized } \\
\boldsymbol{B}\end{array}$ & $\begin{array}{c}\text { Standardized } \\
\boldsymbol{\beta}\end{array}$ & $\boldsymbol{p}$ \\
\hline $\begin{array}{l}\text { Primary Variables: } \\
\text { Birth parent anxiety }\end{array}$ & $0.01(0.02)$ & $0.03(0.05)$ & 0.48 \\
\hline
\end{tabular}

Note: $N=489$; Numbers outside of parentheses are parameter estimates, numbers inside parentheses are $S E s$. 
Table 4

Structural Equation Model Results for Primary Outcomes: Fathers

\begin{tabular}{|c|c|c|c|}
\hline & Unstandardized & Standardized & $p$ \\
\hline \multicolumn{4}{|l|}{ Outcome: 18-month social inhibition } \\
\hline \multicolumn{4}{|l|}{ Covariates: } \\
\hline Openness of Adoption & $-0.13(0.05)$ & $-0.14(0.06)$ & 0.02 \\
\hline Sex of Infant & $-0.06(0.10)$ & $-0.04(0.06)$ & 0.54 \\
\hline Adoptive Parent Education & $-0.03(0.03)$ & $-0.05(0.06)$ & 0.42 \\
\hline Pregnancy Complications & $-0.01(0.02)$ & $-0.03(0.06)$ & 0.61 \\
\hline \multicolumn{4}{|l|}{ Primary Variables: } \\
\hline Child-centered parenting & $-0.01(0.03)$ & $-0.02(0.06)$ & 0.75 \\
\hline Birth parent anxiety & $0.01(0.01)$ & $0.06(0.06)$ & 0.29 \\
\hline Child-centered parenting* Birth parent anxiety & $0.01(0.00)$ & $0.19(0.07)$ & 0.01 \\
\hline 9-month social inhibition & $0.06(0.04)$ & $0.10(0.06)$ & 0.08 \\
\hline Paternal anxiety & $0.02(0.02)$ & $0.07(0.06)$ & 0.22 \\
\hline \multicolumn{4}{|l|}{ Outcome: Child-centered parenting } \\
\hline \multicolumn{4}{|l|}{ Covariates: } \\
\hline Openness of Adoption & $0.09(0.09)$ & $0.05(0.05)$ & 0.33 \\
\hline Sex of Infant & $0.11(0.16)$ & $0.03(0.05)$ & 0.52 \\
\hline Adoptive Parent Education & $0.27(0.06)$ & $0.23(0.05)$ & $<0.01$ \\
\hline Pregnancy Complications & $0.02(0.03)$ & $0.11(0.05)$ & 0.02 \\
\hline \multicolumn{4}{|l|}{ Primary Variables: } \\
\hline Birth parent anxiety & $0.00(0.01)$ & $0.00(0.05)$ & 0.99 \\
\hline 9-month social inhibition & $-0.01(0.08)$ & $-0.01(0.06)$ & 0.90 \\
\hline Paternal anxiety & $-0.02(0.03)$ & $-0.04(0.05)$ & 0.40 \\
\hline \multicolumn{4}{|l|}{ Outcome: 9-month social inhibition } \\
\hline \multicolumn{4}{|l|}{ Covariates: } \\
\hline Openness of Adoption & $-0.07(0.08)$ & $-0.05(0.06)$ & 0.43 \\
\hline Sex of Infant & $0.00(0.15)$ & $0.00(0.06)$ & 0.99 \\
\hline Adoptive Parent Education & $-0.01(0.05)$ & $-0.01(0.06)$ & 0.87 \\
\hline Pregnancy Complications & $0.06(0.02)$ & $0.13(0.06)$ & 0.02 \\
\hline \multicolumn{4}{|l|}{ Primary Variables: } \\
\hline Birth parent anxiety & $-0.01(0.01)$ & $-0.04(0.06)$ & 0.47 \\
\hline Paternal anxiety & $-0.01(0.02)$ & $-0.02(0.06)$ & 0.71 \\
\hline \multicolumn{4}{|l|}{ Outcome: Paternal anxiety } \\
\hline \multicolumn{4}{|l|}{ Covariates: } \\
\hline Openness of Adoption & $-0.09(0.16)$ & $-0.03(0.05)$ & 0.57 \\
\hline Sex of Infant & $0.08(0.29)$ & $0.01(0.05)$ & 0.79 \\
\hline Adoptive Parent Education & $0.08(0.06)$ & $0.04(0.05)$ & 0.45 \\
\hline Pregnancy Complications & $0.02(0.05)$ & $0.02(0.05)$ & 0.67 \\
\hline
\end{tabular}

Primary Variables: 


\begin{tabular}{lccc}
\hline & Unstandardized & Standardized & $\boldsymbol{p}$ \\
\hline Birth parent anxiety & $-0.02(0.02)$ & $-0.06(0.05)$ & 0.22 \\
\hline
\end{tabular}

Note: $N=476$; Numbers outside of parentheses are parameter estimates, numbers inside parentheses are $S E \mathrm{~s}$. 